\title{
COMO AS SERPENTES, FORMOSAS, MAS VENENO- SAS, INSINUANTES, MAS TRAIÇOEIRAS: AS MUL- HERES E A VIOLENCIA NO ALTO MINHO ENTRE OS FINAIS DE OITOCENTOS E O DEALBAR DO SÉCULO XX ${ }^{1}$
}

\author{
Alexandra ESTEVES \\ Universidade do Minho
}

\begin{abstract}
RESUMEN: Es nuestro objetivo analizar las acciones de violencia en las que eran victimas las mujeres del Alto Minho, región situada al Norte de Portugal, durante el siglo XIX y la primera mitad del siglo XX. En consecuencia de una elevada emigración masculina, iniciada a finales del siglo XVIII y cuyo principal destino era Brasil, la mujer, además de gobernar la casa, empezó también a asumir un conjunto de tareas consideradas típicamente masculinas, obligándola a abandonar la seguridad del espacio doméstico, lo que, en consecuencia, le proporcionará nuevas formas de sociabilidad y el acceso a espacios que hasta entonces le eran prohibidos.
\end{abstract}

PALABRAS CLAVE: mujer, Alto Minho, violencia, crimen.

ABSTRACT: It is our goal to analyze actions of violence that women were victims in the Alto Minho, region located in the North of Portugal, during the $19^{\text {th }}$ and the first half of the $20^{\text {th }}$ century. As a result of high male emigration, which began in the late eighteenth century and that had Brazil as main destination, the woman of Alto Minho beyond the government of the house, also passed to assume a number of tasks viewed as typically male, forcing her to leave the seclusion of domestic space, which, therefore, it provided new forms of sociability and access to spaces that until now were banned to her.

KEYWORDS: woman, Alto Minho, violence, crime.

\section{DESENHANDO CONTEXTOS}

Em finais do século XIX e no início do século XX, o Alto Minho, situado no Norte de Portugal, tinha uma população que se dedicava à agricultura, embora as gentes das zonas ribeirinhas também procurassem na actividade piscatória o sustento que o cultivo da terra, por si só, não garantia. Dada a pouca expressão do comércio e da indústria, eram as feiras e os mercados, que aconteciam,

\footnotetext{
${ }^{1}$ Recibido el 7 de julio y aceptado para su publicación el 29 de septiembre de 2010.
} 
periodicamente, em todas as vilas e em algumas aldeias do distrito de Viana do Castelo, e onde decorria a transaç̧ão de todo o tipo de produtos, que desempenhavam o papel de principais impulsionadores da economia da região.

As poucas estradas, muitas delas em estado muito precário, também não facilitavam a circulação de pessoas e bens, ainda que, na segunda metade do século XIX, se tivesse procedido ao alargamento da rede viária e à realização de obras de beneficiação na existente. O caminho-de-ferro, que liga Viana do Castelo ao Porto foi inaugurada em 1878, e a ligação à Galiza, província do Norte de Espanha, aconteceu mais tarde. Todavia, as populações ribeirinhas não deixavam de tirar proveito da proximidade do mar e da navegabilidade dos rios Minho e Lima para as suas deslocações e para comerciar os produtos. ${ }^{2}$

Sobretudo a partir de finais do século XVIII, a região alto minhota conheceu importantes surtos migratórios, para os quais contribuiu, em larga medida, a insuficiência de meios de subsistência para responder ao crescimento populacional.

O papel desempenhado pela mulher do Alto Minho, nomeadamente na sociedade e na actividade económica, e até no desvio, foi influenciado, em boa parte, pelos movimentos migratórios que levaram muitos homens a abandonar as suas terras, o que, por sua vez, conduziu a uma certa efeminização da mão-de-obra. A mulher deixou de estar confinada à família e ao lar, passando a ter uma vivência mais pública e mais exposta. Era frequente ser a mulher a amanhar a terra, a cuidar do gado, a fazer a sementeira, a tratar da rega e a organizar a colheita. ${ }^{3}$ Era ela que partia para as feiras, não apenas para comprar, mas também para vender animais ou uma parte da sua produção agrícola. Era ela que ia aos montes colher a lenha ou roçar o mato, que zelava as vinhas e as árvores de fruto. ${ }^{4}$ Também era ela que animava as feiras, as festas e os serões. Mas a mulher também passou a ganhar

${ }^{2}$ Sobre a chegada do caminho-de-ferro ao Alto Minho, leia-se R. FEIJÓ (1992). Liberalismo e Transformação Social. A Região de Viana do Antigo Regime à Regeneração. Lisboa: Editorial Fragmentos, p. 153.

${ }^{3}$ Sobre a importância da mão-de-obra feminina para os trabalhos do campo e para a economia familiar, leia-se sobre as comarcas de Penamacor, Montemor-o-Velho e Coimbra, I. M. VAQUinHAS (1990). Violência, Justiça e Sociedade Rural. Os campos de Coimbra, Montemor-o-Velho e Penacova de 1858 a 1911. Coimbra: Faculdade de Letras, 1990, pp. 314- 331. Tese de doutoramento policopiada.

${ }^{4}$ Segundo João de Pina Cabral, no mundo rural agrícola alto minhoto, existe uma espécie de divisão sexual do trabalho, havendo tarefas que estavam vedadas às mulheres, como, por exemplo, subir às árvores ou podar as videiras. Confira-se J. PINA CABRAL (1989). Filhos de Adão, Filhas de Eva. A visão do mundo camponesa no Alto Minho. Lisboa: Publicações Dom Quixote, p. 110. 
destaque nos conflitos que, de vez em quando, punham em sobressalto o quotidiano das populações.

No intuito de caracterizarmos o papel da mulher no mundo da criminalidade, não apenas enquanto vítima, mas igualmente como protagonista de acções delituosas, optámos por analisar os Autos de Corpo de Delito realizados em Ponte de Lima e em Caminha, dois concelhos do Alto Minho, referentes aos períodos compreendidos entre 1894 e1899 e entre 1923 e 1928, respectivamente.

Em finais de oitocentos, Ponte de Lima, à semelhança do que acontecia noutros concelhos do Alto Minho, apresentava um comércio modesto, uma indústria apagada e uma agricultura predominante. ${ }^{5}$ Também aqui os efeitos da emigração masculina se fizeram sentir nos comportamentos da mulher, que evidenciavam uma maior desenvoltura e uma vivência mais pública, quando comparada com outras regiões do país. Em Caminha, nos inícios do século XX, o cenário era idêntico, ainda que, apesar de se tratar de um concelho essencialmente agrícola, a pesca no mar e no rio Minho constituísse uma actividade relevante, até porque proporcionava a muitas famílias das freguesias de Âncora, Caminha, Seixas, Lanhelas e Venade o alimento e o equilíbrio financeiro que a terra nem sempre garantia.

Durante o período compreendido entre 1894 e 1899, no concelho de Ponte de Lima, contabilizámos 992 autos de corpo de delito, sendo que em 72,5\% dos quais surgem como arguidos elementos do sexo masculino. As mulheres surgem nessa condição em apenas $25,1 \%$ dos casos. Em relação aos restantes $2,4 \%$, não foi possível apurar o sexo do arguido. ${ }^{6}$

\footnotetext{
${ }^{5}$ Sobre as indústrias de Ponte de Lima, leia-se M.R. Lemos (1977). Anais Municipais de Ponte de Lima. Braga: Câmara Municipal de Ponte de Lima, pp. 138-139.

${ }^{6}$ Arquivo Municipal de Ponte de Lima, (doravante AMPL), Corpos de delito, n. ${ }^{\circ}$ 1726. Para a comarca de Ponta Delgada, Susana Paula Franco Serpa Silva avança com uma criminalidade e violência predominantemente masculinas, conclusões alicerçadas em fontes de carácter judicial para o período compreendido entre 1830 e 1841. Confira-se S. SILVA (1997). A Criminalidade e a Justiça na comarca de Ponte Delgada. Uma abordagem com base nos processos penais (1830-1841). Ponta Delgada: Universidade dos Açores, pp. 245-257. Tese de mestrado policopiada. Para a Galiza, igualmente com base em fontes de carácter judicial, Raquel Inglesais Estepa verificou que esta província apresentava percentagens modestas no que diz respeito à participação feminina no mundo da criminalidade, no período compreendido entre os finais do Antigo Regime e 1834, surgindo as mulheres como culpadas em 14,65\% das ocorrências, o que era significativo, se atendermos ao facto de na Galiza se registar uma superioridade da população feminina, em resultado da emigração de efectivos masculinos, rumo a Castela, Andaluzia e Portugal. Confira-se R. IgLESIAS EstePA (2007). Crimen, Criminales y reos. La delincuencia y su represión en la antigua província de Santiago entre 1700 y 1834. Vigo: Ediciones Nigratrea, p. 232. Para a comarca de Tavira, estudada por Aurízia
} 
No que diz respeito a Caminha, entre 1923 e 1928 contabilizámos 455 autos de corpo de delito. Em 61,8 \% das ocorrências os arguidos são do sexo masculino, $31,6 \%$ do sexo feminino e nos restantes $6,6 \%$ as autoridades não conseguiram identificar os autores dos delitos. ${ }^{7}$

A posição minoritária ocupada pela mulher no âmbito da criminalidade, na condição de ofensora, subsiste até aos nossos dias, e resulta da sua exclusão do processo de aprendizagem da violência veiculado pela sociedade. Segundo esta perspectiva, o envolvimento da mulher em acções violentas é condicionado pelo seu contacto com o homem, que tende a imitar. A este propósito, Pieter Sieperenburg afirma o seguinte: "The culture of violence, was a male culture and women recognized this. Some might imitate male violence, but they did not step into the male world. Female violence was same-sex violence." ${ }^{8}$ Considera-se igualmente que a mulher tem uma actuação mais restrita na prática de delitos e que o espectro de crimes é muito mais limitado que o do homem, estando associada, sobretudo, às ofensas verbais, à prostituição e ao infanticídio. ${ }^{9}$

Outras perspectivas historiográficas consideram que as mulheres têm sido constantemente sub-representadas nas estatísticas criminais, e que estas não traduzem, de modo fidedigno, a intervenção da mulher no mundo do delito. Esta hipótese é sustentada por diferentes trabalhos históricos que mostram que, no passado, as mulheres surgem mais frequentemente envolvidas nas malhas da justiça do que nos dias de hoje. ${ }^{10}$

Será importante salientar que a disparidade de conclusões sobre a presença feminina na actividade criminosa é condicionada pela diversidade de contextos analisados, por factores externos que interferem nos resultados, bem como pelas fontes, sejam elas de carácter administrativo ou judicial, que, de acordo com a sua natureza, nos permitem aceder a diferentes graus da participação feminina, quer

Anica, a situação é semelhante. $\mathrm{O}$ homem assume-se como principal produtor de violência, liderando no papel de ofensor e ofendido. A. ANICA (2005). A transformação da violência no século XIX. $O$ caso da comarca de Tavira. Lisboa: Edições Colibri, pp. 95-96.

7 Arquivo Distrital de Viana do Castelo (doravante ADVC), Registo dos corpos de delito, processos crimes, nos termos da lei, n. $^{\circ} 4.91 .6 .9$.

${ }^{8}$ Confira-se P. Sieperenburg. (1997). «How violent were women? Court cases in Amsterdam, 1650-1750». Crime, History and Societies, n. ${ }^{\circ}$ 1, vol. 1, pp. 26-27.

${ }^{9}$ Leia-se M. MYERS (2003). «Female crime, History of». In N.H. RAFTER, Encyclopaedia of Women and Crime. New York: Checkmark Books, p. 71.

${ }^{10}$ Confira-se C. ARnot, M. L. y UsBorne (2003). «Why gender and crime? Aspects of an international debate». In M.L. ARnOt. y C. Usborne. (eds.). Gender and Crime in Modern Europe. London: Routledge, pp. 1-43. 
como ofensora, quer como ofendida. Pode-se atender igualmente a estudos de carácter mais micro, antropológico ou de análise linguística, relacionados com a análise e compreensão da criminalidade feminina.

É ainda de salientar que muitas das ocorrências transgressoras não chegavam ao conhecimento das autoridades e menos ainda seriam aquelas que ficavam sob a alçada da justiça, sendo, por conseguinte, de admitir que alguns comportamentos violentos, aos quais não é possível aceder através das fontes, acabavam por ser silenciados e até tolerados por um quotidiano que os normalizava. Deste modo, concluímos que apenas temos acesso a uma parcela das condutas desviantes, sem conseguirmos um conhecimento exaustivo da violência e da criminalidade na sua real dimensão.

Algumas teorias sustentavam a menor propensão da mulher para o conflito, confirmada pela estatística criminal, dadas as suas características fisiológicas e intelectuais. Todavia, estes pontos de vista podem ser contestados e suplantados por outros que remetem para um quotidiano mais limitado no que concerne à sociabilidade fora do espaço doméstico, e ainda para o papel menor que era conferido à mulher pela sociedade em termos correctivos, resultante da sua subalternização, no plano legal e civil, ao elemento masculino. ${ }^{11}$

A escola socialista, que tinha Afonso Costa como um dos nomes destacados em Portugal, sustentava precisamente que o menor número de crimes praticados pelas mulheres não resultava da sua condição física ou de valores morais, mas sim das condições sociais em que viviam. ${ }^{12}$ Consideramos, no entanto, que a ausência do elemento masculino e as condições económicas da região levavam a mulher do Alto Minho a ter uma vivência diária mais pública e mais alargada, quando comparada com a de outras regiões. ${ }^{13}$

${ }^{11}$ Sobre este assunto, confira-se D.C.D. Alves (2003). Violência e Perdão em Óbidos (15951680). Coimbra: Universidade de Coimbra, pp. 104-105. Tese de mestrado policopiada.

12 Confira-se M. A. MALdOnAdo da Silva. Alguns aspectos da história da criminologia em Portugal, trabalho apresentado para o exame do Curso Complementar de Ciências HistóricoJurídicas, sem local de edição, sem editora, sem ano de edição.

${ }^{13}$ Maria João Vaz refere, na sua tese de doutoramento, que, no ano de 1892, o distrito de Viana do Castelo, apresentava uma percentagem de condenações de mulheres de $46 \%$, quando a percentagem média no país rondava os $20 \%$, o que pode ser explicado pelas circunstâncias sociais, culturais e demográficas que se verificavam neste distrito desde finais do século XVIII, e que explicam a maior participação da mulher no mundo da criminalidade. Confira-se M.J. VAZ (2006). A criminalidade em Lisboa entre os meados do século XIX e o início do século XX. Lisboa: Instituto Superior de Ciências do Trabalho e da Empresa, p. 396. Tese de doutoramento policopiada. 
Estas perspectivas opõem-se à da antropologia positivista, liderada por Cesare Lombroso, que considerava que a mulher criminosa podia definir-se, devido à desordem dos costumes, como uma degenerada. ${ }^{14}$ Este autor invocava a maior elevação dos seus valores morais para justificar a menor participação da mulher no mundo da criminalidade. ${ }^{15}$

Outros autores, como Ferreira Deusdado, um liberal católico, consideram que as estatísticas não traduzem a verdadeira dimensão da intervenção da mulher em acções criminosas, e que esta só não é maior por falta de oportunidade e pela dificuldade em aceder aos meios que permitem a prática do delito. Quando dispõe dos instrumentos adequados e em circunstâncias propícias, a mulher suplanta o homem nas estatísticas, dando como exemplo o envenenamento. $\mathrm{Na}$ sua perspectiva, a mulher permanece na penumbra, assumindo o papel de cúmplice e de instigadora de crimes, além de a considerar capaz não só de actos mais cruéis, mas também de acções que exigem alguma premeditação. Vai ainda mais longe ao considerar a mulher "Ora hypocritas, ora ousadas e cynicas, gostam de mentir e de enganar; menos capazes do que o homem do verdadeiro arrependimento (...)."16 Ferreira Deusdado não era o único a vislumbrar a mulher na posição de instigadora, de responsável moral pelo cometimento de crimes protagonizados por homens, movidos pelo propósito de as satisfazer e aos seus vícios. Em resultado desta concepção, verifica-se, como considera Michelle Perrot, uma certa contribuição do pensamento criminológico para a perpetuação do mito de $\mathrm{Eva}^{17}$.

Roberto Frias considerava igualmente que as estatísticas da época, referentes a diversos países, não reflectiam a real extensão do envolvimento da mulher em actos delituosos, devido à natureza dos mesmos, pois tratava-se de crimes de mais fácil encobrimento, o que provocava a ausência de informação rigorosa junto da opinião pública, a distorção dos números das estatísticas e a fuga às malhas da justiça.

A prostituição era apontada por este autor como uma das principais responsáveis pela presença da mulher no mundo da criminalidade. Mulheres que

${ }^{14}$ M. Tsikounas (2008). Éternelles Coupables. Les femmes criminalles de l'Antiquité à nos jours. Paris: Éditions Autrement, p. 8.

15 A. Costa (1895). Comentário ao Código Penal Português, vol. 1, Introdução-Escolas e principios da criminologia moderna. Coimbra: Imprensa da Universidade, pp. 261-262.

16 M.A. Ferreira-Deusdado (1889). Estudos sobre Criminalidade e Educação, Lisboa: Imprensa Evangelista Lucas Torres, p. 51.

${ }^{17}$ Confira-se M. PERROT (1988). Os Excluidos da História: Operários, mulheres e prisioneiros. Rio de Janeiro: Paz e Terra, pp. 255-258. 
exerciam diversos ofícios, como costureiras ou criadas de servir, não tinham qualquer pejo em entregar-se à meretrícia clandestina. Tal circunstância permite estabelecer a ligação entre a prostituição e a criminalidade, alicerçada nos estudos invocados pelo autor, que revelam uma maior tendência para a reincidência na acção delituosa por parte dos elementos do sexo feminino. No caso das mulheres, Frias afirmava que a menstruação ou a gravidez são estados orgânicos que influenciam a sua predisposição para o crime. ${ }^{18}$

Afonso Costa, por seu lado, considerava que a mulher igualava o homem no campo da perversidade e ia mais longe, ao considerar que o sexo não deve ser entendido como um factor a ter em conta na avaliação da criminalidade. ${ }^{19}$

Já Mendes Corrêa, com base na baixa representatividade do género feminino nas estatísticas produzidas em Portugal, entre finais do século XIX e os inícios do século XX, bem como nas que foram produzidas noutros países, como Inglaterra, França e Rússia, concluiu que existia, de facto, uma menor propensão da mulher para o crime, quando comparada com o homem. Esta realidade ganhava particular relevância, no caso português, pela circunstância de a população feminina ser superior à masculina. ${ }^{20}$

Para Mendes Corrêa, a menor participação da mulher era explicada, não apenas pelas razões invocadas pela escola da antropologia criminal, baseadas nas virtudes e nos defeitos inerentes a cada sexo, mas igualmente por factores de ordem física e pela personalidade, alegando que "as suas paixões, as suas taras, os seus ímpetos, encontram ao seu serviço energias que não existem geralmente em tão alto grau no sexo fraco", bem como pela vida socialmente activa do homem, em contraste com a vida mais recatada da mulher. ${ }^{21}$ No entanto, para este autor, a criminalidade feminina estava a aumentar em finais de oitocentos devido a uma certa permissividade da justiça, que se mostrava branda perante a mulher delinquente. Admitia ainda, com base nas estatísticas produzidas entre 1891 e 1895, que existia

${ }^{18}$ R. FRIAS (1880). O crime (Apontamentos para a systematisação da criminalidade). Porto: typ. Alexandre da Fonseca Vasconcellos, pp. 51-54.

19 A. Costa (1895). Comentário ao Código Penal Português, vol. 1, Introdução-Escolas e princípios da criminologia moderna..., pp. 262-263.

20 Segundo Mendes Corrêa, entre 1878 e 1895, as estatísticas produzidas demonstram que o cometimento de crimes era seis a sete vezes mais frequente nos homens do que nas mulheres. Veja-se M. CorrêA, (1914). Os Criminosos Portugueses. Estudos de Anthropologia Criminal. Coimbra: F. França Amado Editor, pp. 68-69.

${ }^{21}$ Consulte-se M. CORRÊA (1914). Os Criminosos Portugueses. Estudos de Anthropologia Criminal..., p. 75. 
uma grande discrepância no território nacional, pois, enquanto que no Sul, em particular no distrito de Beja, a criminalidade feminina era reduzida e o crime era dez vezes mais frequente no homem que na mulher, no Norte, nomeadamente em Viana do Castelo, a criminalidade feminina era muito mais elevada, cometendo o homem apenas três vezes mais delitos que as mulheres. Esta realidade é perceptível a partir de 1878, quando as estatísticas começaram considerar a informação respeitante ao sexo dos criminosos, no sentido de se compreender os autores dos delitos, para melhor evitar a sua ocorrência, desenvolver formas mais eficazes de os penalizar e, consequentemente, extirpar a criminalidade ${ }^{22}$.

Embora a interferência da mulher em actividades criminosas fosse estatisticamente inferior à do homem, também esta será alvo de estudos antropométricos, no sentido de definir a mulher delinquente, através do desenvolvimento de observações de carácter físico e intelectual, sobretudo por parte daqueles que acreditavam que a prática do delito estava dependente de características somáticas.

Segundo as conclusões de Rancoroni, apresentadas em 1894 num congresso médico internacional, publicitadas por Alfredo Luís Lopes na sua obra Estudo estatístico da criminalidade em Portugal nos anos de 1891 a 1895, o comportamento criminal do homem pode ser influenciado negativamente pela civilização e pela instrução, ao passo que, em relação à mulher, a interferência mais perniciosa para o seu comportamento poderia advir do casamento. Para o mesmo autor, as causas da menor presença da mulher nas estatísticas criminais têm a ver com os seus costumes, ocupações e "funcções physiologicas, que não permittem um grande desenvolvimento dos centros superiores do cérebro" ${ }^{23}$

Mesmo perante o crime, a mulher era, por vezes, desculpabilizada e desresponsabilizada pelos seus actos, em resultado da sua pretensa inferioridade física e intelectual. Aires de Gouveia, por exemplo, sustentava que as suas acções eram condicionadas por factores de ordem natural, como a menstruação, que as indispunha, e a sua "menor aptidão para se ilustrar intellectualmente", situação agravada, na sua perspectiva, pelo desmazelo a que tinha sido votada a educação da mulher ${ }^{24}$.

22 Confira-se M.J. VAZ (1998). Crime e Sociedade. Portugal na segunda metade do século XIX. Oeiras: Celta, p. 189.

${ }^{23}$ Confirme-se A. L. Lopes (1897). Estudo estatístico da criminalidade em Portugal nos anos de 1891 a 1895. Lisboa: Imprensa Nacional, p. 282.

${ }^{24}$ Veja-se A. A. Gouveia (1860). A Reforma das Cadeias em Portugal. Coimbra: Imprensa da Universidade de Coimbra, p. 48. 
O período de finais de oitocentos foi marcado por intenso debate sobre a relação da mulher com o crime, alimentado por concepções díspares e antagónicas sobre a mesma. De um lado, encontramos aqueles que elevam o seu carácter bondoso, acentuam a sua inocência e ingenuidade, outros procuraram salientar a sua natureza pérfida e malévola. ${ }^{25}$ Temos ainda a perspectiva daqueles que se centram em explicações de carácter biológico, de que são exemplo as teorias da escola positivista, e a dos que incidem mais sobre o domínio do social para explicar a intervenção da mulher na actividade criminosa. ${ }^{26}$

Consideramos que, para analisar a criminalidade feminina, não podemos cingirnos apenas ao número de ocorrências em que a mulher é protagonista, mas, pelo contrário, convirá atender às circunstâncias em que se verificou a sua participação e que tipo de delitos praticou. Em Ponte de Lima, por exemplo, constatamos que a mulher aparece na condição de arguida em casos relacionados com atentados cometidos contra pessoas, designadamente ofensas corporais e ofensas à moral, e contra a propriedade, sobretudo furtos. Muito raramente a mulher surge implicada em transgressões que atentam contra o Estado, a tranquilidade e a ordem pública. ${ }^{27}$

Deste modo, a associação da criminalidade feminina apenas a trocas de palavras mais azedas e a calúnias ou injúrias, carece de fundamento, dado que a mulher, facilmente, ultrapassava a barreira do socialmente tolerado e partia para comportamentos mais impetuosos, envolvendo-se em rixas e escaramuças, que, não raras vezes, culminavam na agressão física. Era o que se verificava no caso concreto de Ponte de Lima.

Como se pode verificar no GRÁFICO 1, referente a Ponte de Lima, o crime de ofensas corporais assume uma posição de relevo no âmbito dos crimes imputados à mulher, tendo-se registado, entre 1894 e 1899, 144 participações de delitos desta natureza.

25 Sobre este dualismo, patente no discurso de Oitocentos sobre a criminalidade feminina, consulte-se M. J. VAZ (1998). Crime e Sociedade. Portugal na segunda metade do século XIX..., pp. 82-92.

${ }^{26}$ Sobre as explicações desenvolvidas desde o século XIX sobre a criminalidade feminina, leia-se A. Sullivan (2003). «Female Crime, Explanations of», in N. H. RAFTER, Encyclopaedia of Women and Crime. New York: Checkmark Books, pp. 70-71.

${ }^{27}$ No estudo que realizou para a região de Coimbra, abrangendo o período compreendido entre 1850 e 1915, Irene Vaquinhas aponta igualmente a baixa participação da mulher em atentados contra a ordem e tranquilidade pública, destacando-se antes em delitos menores, como injúrias, ofensas corporais e furtos. I. VAQUiNHAS (2000). "Senhoras e Mulheres", na sociedade portuguesa do século XIX. Lisboa: Edições Colibri, 2000, pp. 148-149. 
Gráfico 1. Crimes de que são acusadas as mulheres no concelho de Ponte de Lima (1894-1899).

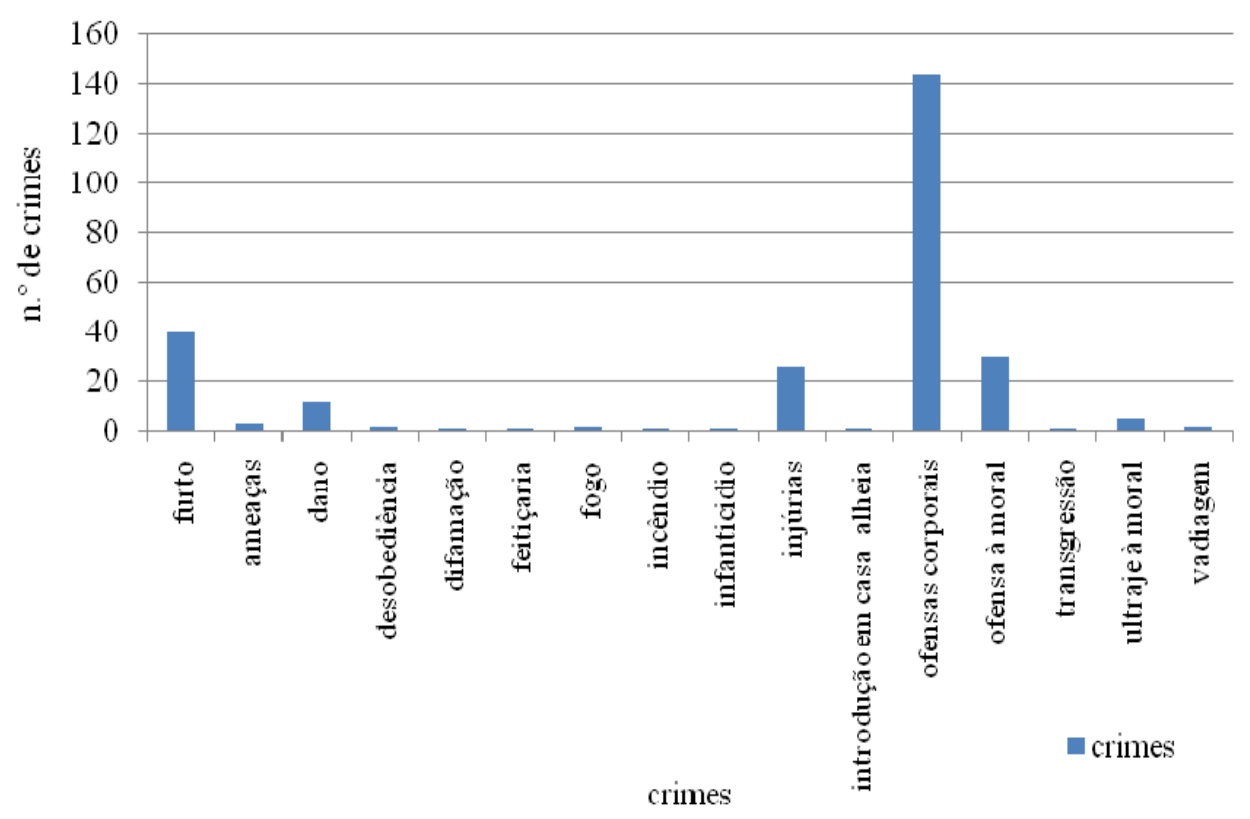

FONTE: AMPL, Corpos de delito, n. $^{\circ} 1726$.

As mulheres agrediam indistintamente homens e mulheres, embora com ligeira incidência sobre os elementos do mesmo sexo. A diferença torna-se mais acentuada quando nos centramos no delito de ofensas corporais. Entre 1894 e 1899, no concelho de Ponte de Lima, encontrámos 58 autos que envolvem exclusivamente elementos do sexo feminino, ao passo que, em igual período, encontrámos apenas 21 processos de agressões físicas cometidas pelas mulheres sobre os homens. ${ }^{28}$ Algumas dessas agressões visaram menores de idade, não tendo sido possível apurar se existia algum laço de parentesco. Nos três casos em que a mulher surge na condição de arguida e o menor como queixoso, o crime em causa é precisamente o de ofensas corporais. ${ }^{29}$

No que respeita às ofensas que se destinavam a agredir moralmente o indivíduo, a mulher usava a sua verve e recorria à palavra como arma para destratar de forma

${ }^{28}$ AMPL, Corpos de delito, n. ${ }^{\circ} 1726$.

${ }^{29}$ AMPL, Corpos de delito, n. ${ }^{\circ} 1726$. 
indiferenciada homens e mulheres. Aliás, as escaramuças verbais eram, certamente, bem mais frequentes do que as fontes indiciam, ainda que não atingissem gravidade bastante para justificar o recurso à justiça.

Gráfico 2. Crimes pelos quais foram acusadas as mulheres de Caminha (1923-1928).

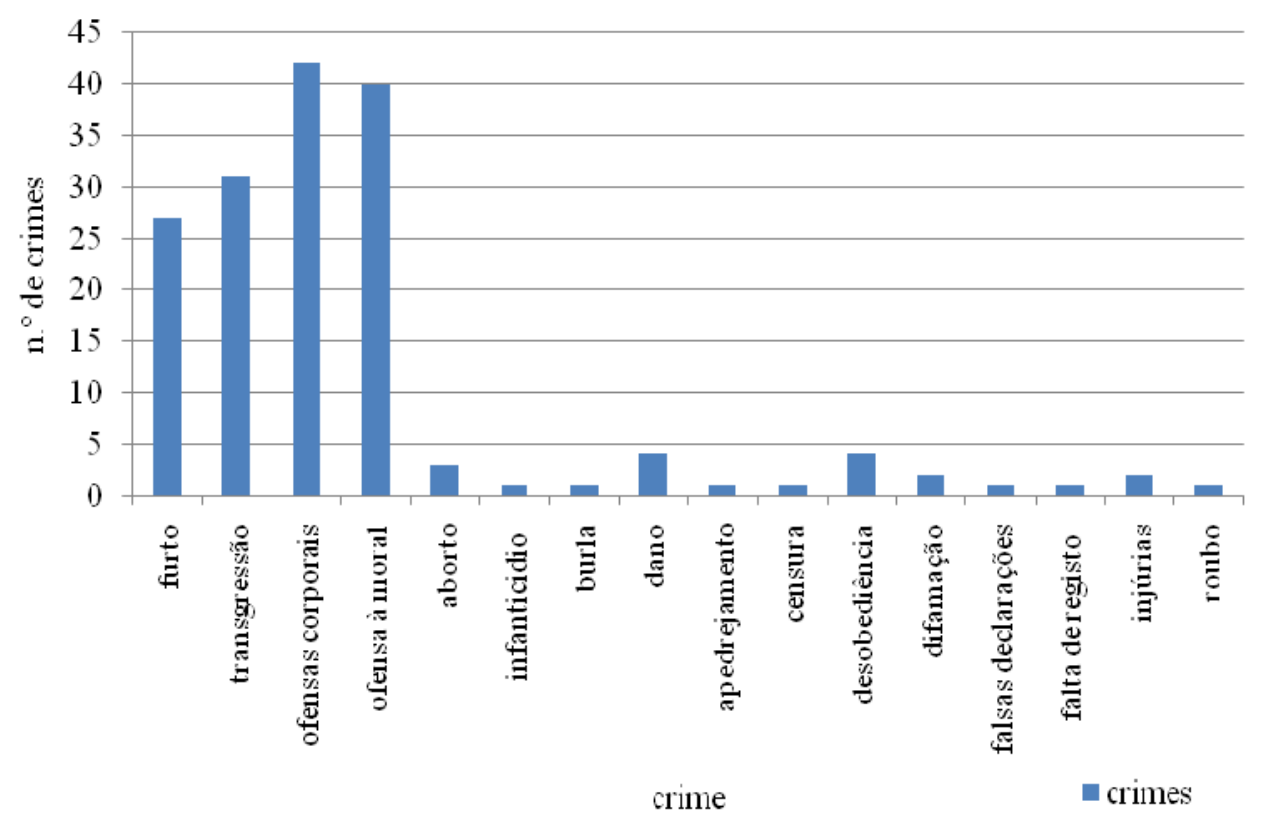

FONTE: ADVC, Registo dos corpos de delito, processos crimes, nos termos da lei, n. ${ }^{\circ}$ 4.91.6.9.

Se considerarmos os dados referentes ao concelho de Caminha, constantes do GRÁFICO 2, constatamos o elevado número de crimes de ofensas corporais e de ofensas à moral protagonizados por mulheres, bem como o envolvimento em pequenas transgressões, não especificadas pelas fontes, que, presumimos, resultam da criminalização de certos comportamentos.

Neste concelho, as mulheres canalizavam a sua fúria para elementos do mesmo sexo. Tomando como exemplo o crime de ofensas corporais, verificamos que, num total de 42 ocorrências registadas durante o período analisado, 27 correspondem a agressões físicas a elementos do sexo feminino e as restantes 15 a elementos do 
sexo masculino. ${ }^{30} \mathrm{O}$ administrador do concelho, os regedores, o chefe da estação de Caminha, o chefe da alfândega, membros dos corpos de segurança ou da guardafiscal constam do rol das vítimas da agressividade feminina. ${ }^{31}$

Em Ponte de Lima, os administradores do concelho também apresentaram queixa contra mulheres, acusadas de envolvimento em actividades relacionadas com a gatunice, a vadiagem e a ofensa à moral. Neste concelho, o ministério público requereu igualmente corpos de delito contra mulheres acusadas de comportamento duvidoso. ${ }^{32}$

Quanto à violência verbal, o panorama era semelhante. As mulheres tendiam mais a agredir verbalmente as suas congéneres. E, mais uma vez, faziam uso do impropério para contestar a autoridade, em particular dos membros da guarda nacional republicana. Aliás, estes guardas eram dos que mais se queixavam, acusando-as de desobediência, furto, difamação e ofensas corporais, o que indicia alguma relutância no acatamento das decisões das autoridades.

Os comportamentos prevaricadores eram protagonizados principalmente por mulheres do povo, de baixa condição social e oriundas da classe trabalhadora. Esta realidade não surpreende, pois eram as que se encontravam mais expostas, enquanto as pertencentes às classes sociais mais elevadas estavam mais resguardadas. No caso particular de Caminha, 48,2 \% das arguidas eram domésticas, dedicando-se à lida da casa. As restantes estavam ligadas a tarefas agrícolas, apresentando-se como lavradeiras e jornaleiras, $21,4 \%$ e $25 \%$, respectivamente. $^{33}$ Este envolvimento das mulheres do campo em condutas transgressoras não resulta da sua maior predisposição para a conflituosidade ou para o crime, mas é facilmente explicável pelo facto de ser na actividade agrícola que se ocupava um maior número de mulheres.

Ainda no que diz respeito à caracterização da mulher delinquente do concelho de Caminha, verificamos que a solidão não pode ser evocada como elemento justificativo da sua opção por comportamentos mais impulsivos ou por atentados cometidos contra a propriedade, dado que, entre as mulheres que especificaram o seu estado civil, 27 eram casadas, 23 solteiras e apenas seis eram viúvas. ${ }^{34}$ Efectivamente, o argumento da desproteç̧ão não pode ser a causa única desta

\footnotetext{
${ }^{30}$ ADVC, Registo dos corpos de delito, processos crimes, nos termos da lei, n. ${ }^{\text {o }}$ 4.91.6.9.

${ }^{31}$ ADVC, Registo dos corpos de delito, processos crimes, nos termos da lei, n. ${ }^{\text {o }}$ 4.91.6.9.

32 AMPL, Corpos de delito, n. ${ }^{\mathrm{o}} 1726$.

${ }^{33}$ ADVC, Registo dos corpos de delito, processos crimes, nos termos da lei, n. ${ }^{\text {o }}$ 4.91.6.9.

${ }^{34} \mathrm{ADVC}$, Registo dos corpos de delito, processos crimes, nos termos da lei, n. ${ }^{\text {o }}$ 4.91.6.9.
} 
inclinação para o delito, embora não saibamos se as mulheres casadas tinham os maridos emigrados no Brasil, em Lisboa ou até na vizinha Galiza.

Traçar o perfil dos protagonistas de acções mais impulsivas, que atentam contra as pessoas, a propriedade ou a tranquilidade pública, afigura-se de primordial importância para a compreensão da própria violência, tendo em consideração os seus intervenientes, quer na condição de ofensores, quer na de ofendidos. ${ }^{35} \mathrm{~A}$ mulher do concelho de Caminha que enveredava por comportamentos considerados criminosos, pertencia às camadas populares, analfabeta, trabalhadora agrícola ou doméstica, casada ou solteira.

Traçando uma linha de continuidade temporal entre os dados fornecidos pelos dois concelhos da mesma região, verificamos uma tendência para o crescimento dos crimes de ofensa verbal em detrimento dos delitos de ofensas corporais, o que pode significar um maior refinamento do comportamento feminino. A mulher, ao conseguir controlar as suas emoções, reage de forma menos instintiva e mais racionalizada, ainda que não totalmente, pois continua a manifestar a sua rudeza e agressividade através do lançamento de impropérios e calúnias. No entanto, ao recorrer ao ataque verbal em vez das ofensas físicas, a mulher vai-se afastando de uma criminalidade mais gravosa, que se mantém como apanágio dos elementos do sexo masculino. Importa, no entanto, salientar que, nos concelhos de Ponte de Lima e Caminha, predominava a pequena criminalidade, senda rara a ocorrência de crimes de grande violência, como homicídios. ${ }^{36}$

Porém, há um crime que registava uma elevada participação feminina, quer no concelho de Ponte de Lima em finais do século XIX, quer no de Caminha, no século XX. Trata-se do delito de furto. Presumimos que este delito esteja conectado com a necessidade de garantir a sobrevivência, saciar a fome e escapar à miséria. Se atendermos à realidade dos dois concelhos, salvaguardadas as devidas diferenças temporais, podemos constatar o predomínio do furto sobre o roubo.

\footnotetext{
${ }^{35}$ No estudo da relação entre a mulher e o crime são considerados fundamentais e precursores os trabalhos produzidos nas décadas de 70 e 80, na França, por Nicole Castan, Les exigences d'ordre et les voies du ressentiment dans une societé pré-revolutionnaire (1750-1790), Toulouse, 1980 e para a Inglaterra o trabalho de J. M. BEATTIE, «The Criminality of women in Eighteenth-century England», publicado em 1875, no Journal of Social History. Sobre estes trabalhos e a história da criminalidade feminina leia-se J.W. Scott y O. Hufton (1983). «Women in History». Past and Present, n. ${ }^{\circ} 101$, pp. 139-140.

${ }^{36}$ No caso de Caminha, no decorrer do período analisado, foram registados três homicídios. ADVC, Registo dos corpos de delito, processos crimes, nos termos da lei, n. ${ }^{\circ}$ 4.91.6.9. Em Ponte de Lima, entre 1894 e 1899 foram registados cinco crimes desta natureza. AMPL, Corpos de delito, n. ${ }^{\circ}$ 1726.
} 
Assim, consideramos apropriado apelidar estas mulheres de simples larápias em vez de grandes ladras.

$\mathrm{O}$ aborto e o infanticídio, crimes tipicamente femininos, registavam uma baixa incidência, o que se explica pela facilidade com que poderiam passar despercebidos aos olhos da sociedade e da justiça. E, mesmo quando descobertos, o seu conhecimento não era sinónimo de condenação. Estes crimes, geralmente premeditados e intencionais, foram encarados, ao longo dos tempos e conforme os lugares, de modo distinto, designadamente quanto à sua punição. As mulheres, induzidas por promessas de casamento não concretizadas ou envolvidas em relações adúlteras, vítimas de estupro ou violações, procuravam eliminar a marca da sua desonra. A pobreza também era, por vezes, um factor que levava à prática destes delitos. Sustentar mais uma boca não era tarefa fácil para quem, sem qualquer apoio, tinha que enfrentar, diariamente, todo o tipo de carências. Por outro lado, o período de gravidez limitava a mulher nos afazeres domésticos e na lida do campo, embora, pouco tempo após o parto, a mulher minhota retomasse as tarefas habituais e as crianças, ainda em idade precoce, começassem a ajudar os pais.

Muitas vezes, na prática destes crimes, as mulheres não actuavam sós, contavam com a conivência de familiares, que não desejavam ver a sua honra manchada em resultado de uma gravidez interdita, por ser concebida fora do sacramento do matrimónio. Por isso, os pais dispunham-se a auxiliar as filhas no cometimento destes actos, o que os colocava também sob a alçada da justiça.

\section{A MULHER ENQUANTO VÍTIMA}

Embora a mulher não assumisse na sociedade alto minhota de finais de oitocentos e primórdios do século XX uma posição passiva, ela acabava por ser vítima de comportamentos mais impetuosos empreendidos não só por elementos do sexo masculino, mas igualmente pelas suas congéneres. Muitas acções resultavam da ausência de recato e da necessidade da mulher se expor para conseguir levar a cabo as tarefas necessárias para acautelar a economia familiar. Por isso, ela circulava por caminhos, ruas, estradas; deambulava por campos e montes; ia ao moinho, à venda, ao mercado, à feira e à festa ${ }^{37}$ Por outro, era a ela que competia, por vezes, resolver sozinha questões relacionadas com a gestão das propriedades, como, por exemplo, a partilha de águas ou o roço dos montes, que, no Alto Minho, constituíam um dos principais motivos de quezílias e desavenças entre famílias e até entre comunidades.

\footnotetext{
${ }^{37}$ Venda - taberna onde se vende; estalagem no campo ou taberna de estrada.
} 
Deste modo, o papel interventivo que a mulher tinha no quotidiano expunhamna mais a situações que atentavam contra a sua integridade física e moral, nomeadamente a crimes de natureza sexual, como a violação e o desfloramento. Estes delitos raramente caíam nas malhas da justiça, muitas vezes graças à cumplicidade de toda a comunidade, que, além de os encobrir, chegava mesmo a desculpabilizá-los. Esta circunstância, por sua vez, alerta para a necessidade de nos precavermos contra o risco de os elementos disponíveis serem considerados suficientes para sustentar uma apreciação objectiva sobre a prática destes atentados e, por via disso, incorrermos em conclusões precipitadas. ${ }^{38}$

A vergonha e a desonra que recaíam sobre as vítimas, mas que se podiam estender ao agregado familiar, explicam a ocultação deste tipo de crimes. No caso da mulher, o estupro ou a violação podiam significar a perda de todo um património futuro, que dependia do estado da sua honra, do grau de pureza e da garantia da virgindade, elementos fundamentais para o contraimento do matrimónio. ${ }^{39} \mathrm{~A}$ honra feminina estava intimamente associada à conduta sexual da mulher, sendo a castidade o seu bem imaterial mais importante. Logo, a mulher desonrada, desflorada ou violada veria as aspirações matrimoniais seriamente prejudicadas, por isso se inibia de recorrer à justiça, dado que toda a sua vida seria exposta e a sua intimidade devassada. Deste modo, entre o agressor e a vítima havia um pacto de silêncio tácito, que protegia o prevaricador e favorecia o cometimento de tais actos. Este sabia de antemão que à sua vítima em nada interessava denunciá-lo, pois o contrário significava sujeitar-se ao risco da difamação e da desonra ${ }^{40}$.

${ }^{38}$ Sobre o carácter impreciso da noção de violência sexual, veja-se X. RouSSEAUX (2002). «La violencia en las sociedades premodernas: Nivelles, una ciudad de Brabante a lo largo de cinco siglos». In J. I. ForteA; J. E. Gelabert y T. A. MANTECón (eds.). Furor et Rabies. Violencia, conflicto y marginación en la Edad Moderna, Santander: Publicaciones de la Universidad de Cantabria, p. 135.

${ }^{39}$ Veja-se H. R. Silva y S. CARDOSO (2004). «Escrituras de perdão num notário do Porto (16501700)». Revista da Faculdade de Letras. História, III Série, vol. 5, pp. 177-178. Segundo Anna Clark, em finais do século XVIII, na Inglaterra, uma mulher violada tinha a sua honra irrevogavelmente manchada, mesmo que se tivesse debatido. Tal resultava da imposição de valores burgueses, que conduziram à valorização da virgindade. Segundo a mesma autora, a desonra era tal que, em Londres, alguns maridos, sabendo que as suas mulheres tinham sido violadas, usavam esse pretexto para se separar delas. A. Clark (1987). Women's Silence, Men's Violence. Sexual Assault in England 17701845. London and New York: Pandora, p. 33.

40 Situação semelhante se verificava na Galiza. Veja-se R. IgLESIAS EstePA (2007). Crimen, Criminales y reos. La delincuencia y su represión en la antigua província de Santiago entre 1700 y 1834 ..., pp. 88-95. 
Nem sempre era a mulher ou o homem que requeriam Auto de Corpo de Delito, podendo esse procedimento ser solicitado por um familiar, pelo administrador do concelho, pela guarda nacional republicana, ou por outra entidade. Nestes casos, o sexo e a identidade da vítima não são conhecidos. Esta situação verificou-se, no século XX, no concelho de Caminha. No período analisado, contabilizámos a existência de quatro casos de violação, mas em apenas dois sabemos a identidade dos queixosos, que supomos serem as vítimas. Nas outras duas ocorrências, a queixa é apresentada pelo administrador e pela guarda nacional republicana de Caminha. ${ }^{41}$

Gráfico 3. Crimes protagonizados pelos homens sobre mulheres em Ponte de Lima (1894-1899).

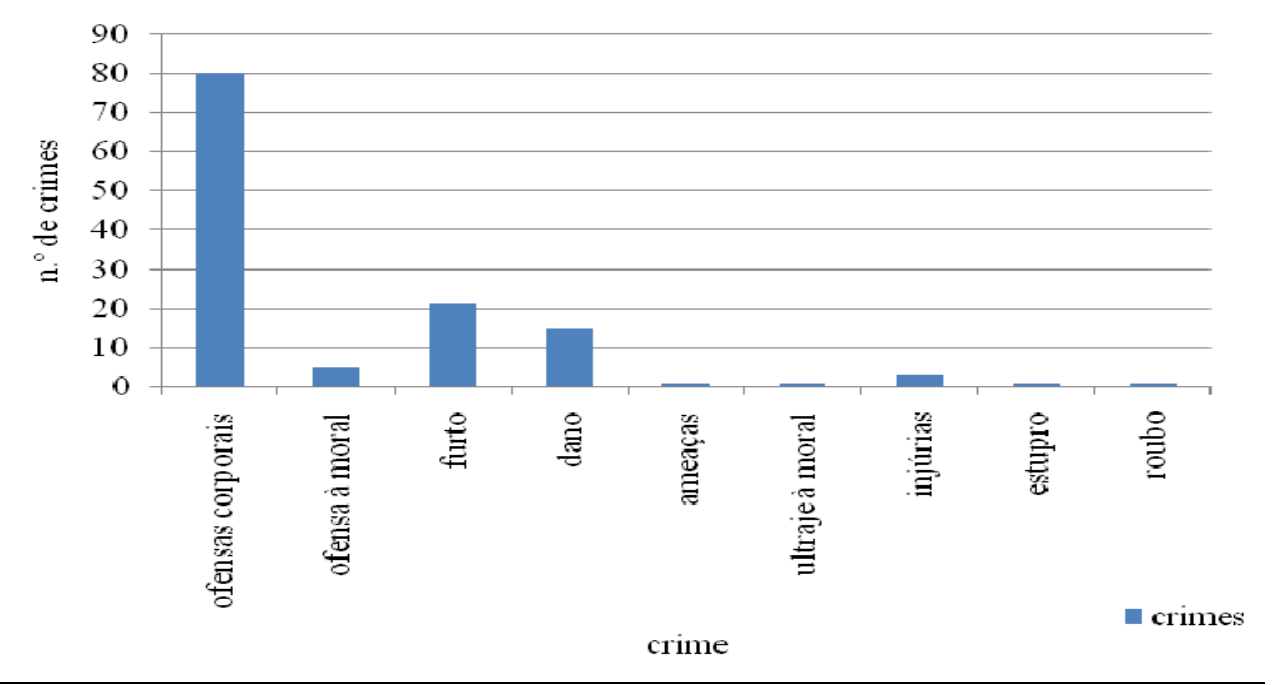

FONTE: AMPL, Corpos de delito, n. ${ }^{\circ} 1726$.

Atendendo aos GRÁFICOS 3 e 4, que se reportam aos crimes cometidos sobre mulheres, constatamos que, tanto em Ponte de Lima como em Caminha, se regista uma baixa incidência de delitos desta natureza. Em contrapartida, verificamos que o crime mais cometido pelos homens dos dois concelhos sobre os elementos do

\footnotetext{
${ }^{41}$ ADVC, Registo dos corpos de delito, processos crimes, nos termos da lei, n. ${ }^{\circ} 4.91 .6 .9$, p. $936 \mathrm{e}$ p. 942.
} 
Como as serpentes, formosas, mas venenosas, insinuantes, mas traiçoeiras: as mulheres e a violência...

sexo oposto era o de ofensas corporais, incluindo o espancamento e o apedrejamento $^{42}$.

Gráfico 4. Crimes protagonizados pelos homens sobre mulheres em Caminha (19231925).

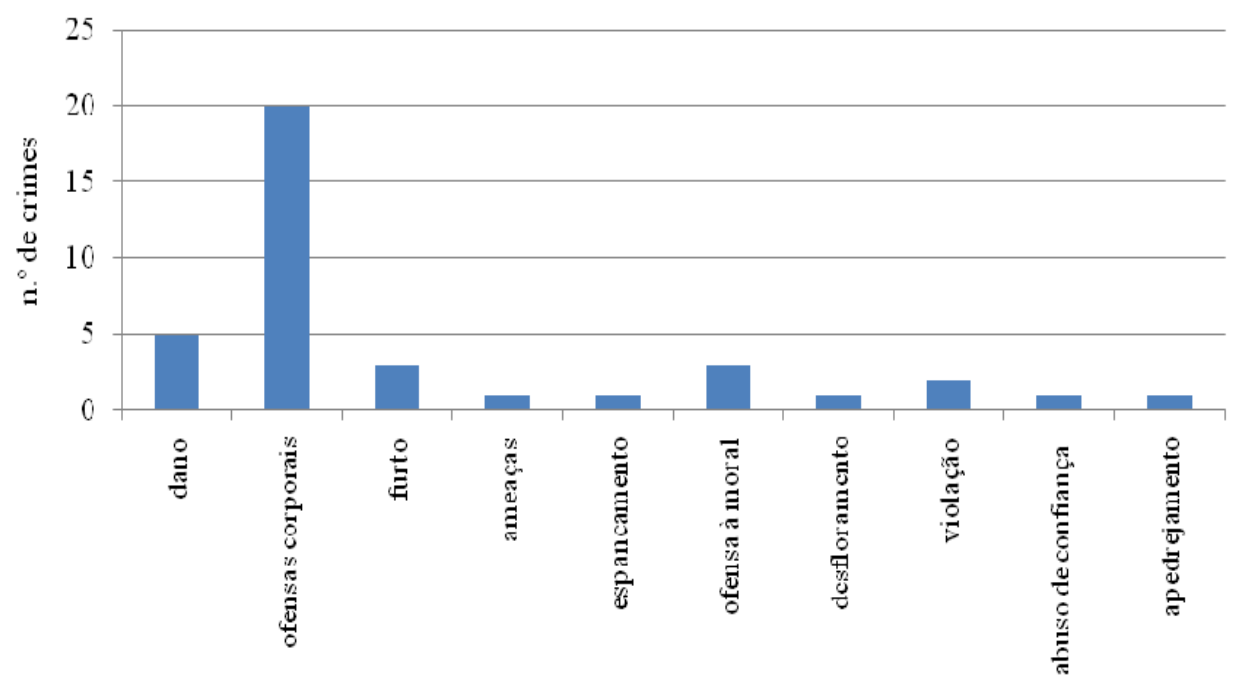

crimes

crime

FONTE: AMPL, ADVC, Registo dos corpos de delito, processos crimes, nos termos da lei, n. ${ }^{\circ}$ 4.91.6.9.

Entre as várias razões que poderão explicar esta aparente predisposição do homem para agredir elementos do sexo oposto, fisicamente mais frágeis, podemos adiantar os seguintes:

As agressões surgiriam em resposta a provocações ou a impropérios vexatórios que lhes eram dirigidos. Aliás, a mulher alto minhota, em particular a do mundo rural, não primava pela contenção na palavra e no

42 Sobre o uso da pedra enquanto arma de recurso nas contendas que envolviam os habitantes de Ponte de Lima, na primeira metade do século XIX, veja-se A. EsTEVES (2009). "Violência e conflitualidade em Ponte de Lima na primeira metade do século XX». In IV Congresso Histórico de Guimarães. Do Absolutismo ao Liberalismo. Actas. vol. I, Braga: Câmara Municipal de Guimarães, p. 314. 
gesto, mas, bem pelo contrário, facilmente assumia uma postura desafiadora e não se inibia de recorrer ao calão mais grosseiro para enxovalhar fosse quem fosse.

$\checkmark \mathrm{O}$ à vontade com que a mulher circulava pelos espaços públicos e participava em eventos impulsionadores de relações de sociabilidade expunham-na mais ao risco de envolvimento em cenas de conflituosidade e violência, muitas vezes potenciadas pelo consumo excessivo de álcool, o que acontecia em vendas e tabernas, nas feiras e nas festas, ou por ocasião dos trabalhos agrícolas. ${ }^{43}$

A participação activa da mulher no mundo do trabalho, sobretudo nas lides do campo, proporcionava um relacionamento mais próximo, mas nem sempre pacífico, entre homens e mulheres, que daria azo a confrontos resultantes do desgaste diário das próprias relações e de posições antagónicas sobre a organização e realização das tarefas agrícolas.

$\checkmark$ A autoridade feminina, bem como o seu poder económico e o seu papel como gestora de bens materiais, decerto que não colhiam a simpatia do

${ }^{43}$ Segundo Irene Vaquinhas, desde finais do século XIX, mas sobretudo a partir dos inícios do século XX, cresceu a intolerância face ao jogo, considerado elemento causador do aumento da criminalidade, instigador do ócio e de promover o desrespeito pelos valores dominantes da família e do trabalho. Sobre o jogo, no período compreendido entre finais do século XIX e início do século XX, leia-se I. VAQUINHAS (2006). Nome de Código "33856". "Os jogos de fortuna ou azar" em Portugal entre a repressão e a tolerância (de finais do século XIX a 1927). Lisboa: Livros Horizonte, pp. 1720. No que diz respeito ao álcool, a sua penetração no mundo rural europeu generalizou-se e, em algumas regiões, assumiu um carácter endémico e degenerativo, a partir da década de setenta e oitenta da centúria de oitocentos. Não se constata, para o campo, na primeira metade da centúria de oitocentos de uma clara associação entre o álcool e os seus efeitos degenerativos, quer do ponto de vista físico quer social. A. CORBIN (1990). "Os bastidores". In G. Duby y P. ARIÉs (dir). História da Vida Privada. Do Renascimento às Luzes. vol. 4, Porto: Edições Afrontamento, pp. 584-585. Todavia, no estudo realizado para a Inglaterra, Barbara Weinberger apresenta taxas de ofensas por alcoolismo mais elevadas para o campo do que para a cidade, numa análise que cobre o período compreendido entre 1860 e 1910. B. WeInBERGER (1996). «Urban and Rural Crime Rates and Their Genesis in Late Nineteenth-and Early Twentieth-century Britain». In H. MonKKONEN y E. A. Johnson (eds.). The Civilization of Crime. Violence in Town and Country since the Midlle Ages. Illinois: University of Illinois Press, pp. 204-205. Acerca dos efeitos do álcool e da sua relação com a criminalidade em Portugal, leia-se I. VAQuinHAS (1992). "Alguns aspectos da violência rural nas comarcas de Coimbra, Montemor-o-Velho e Penacova de 1858 a 1918». Ler História, no 23, pp. 2359. Sobre as tabernas de Lisboa, entre meados do século XIX e inícios do século XX, enquanto palcos de comportamentos arrebatados e agressivos, veja-se M. J. VAZ (2006). A Criminalidade em Lisboa entre meados do século XIX e o início do século XX..., pp. 604-609. Tese de doutoramento policopiada 
Como as serpentes, formosas, mas venenosas, insinuantes, mas traiçoeiras: as mulheres e a violência ...

chamado "sexo forte".

Sobretudo no espaço doméstico, o chefe da casa, ou seja, o homem, não hesitaria, por vezes, em recorrer à violência física para afirmar a sua autoridade sobre a esposa e as filhas.

A mulher também era alvo de comentários e insinuações que visavam denegrir a sua integridade moral, cujos efeitos poderiam ser mais perniciosos e duradoiros que os provocados por agressões físicas. A palavra assumia um valor simbólico, associada a vinganças privadas ou a códigos de honra desrespeitados, sobretudo num espaço marcado pela dureza do quotidiano, como era o mundo rural. ${ }^{44} \mathrm{~A}$ vociferação de certos impropérios, a atribuição de certos adjectivos à conduta da mulher e o lançamento na praça pública de certas calúnias podiam manchar seriamente a sua imagem, sobretudo quando eram dirigidos à sua honra, podendo comprometer seriamente as suas pretensões matrimoniais, caso se tratasse de uma rapariga em idade casadoira. Independentemente do contexto, o comportamento sexual feminino que desrespeitasse os cânones estabelecidos era condenado sem apelo nem agravo, mas o mesmo não acontecia com o homem, embora a frequência de prostíbulos ou o recurso à meretrícia também servissem de pretexto para a difamação. ${ }^{45}$

Quando as injúrias eram proferidas contra uma mulher casada, a desonra estendia-se ao marido, que tinha como obrigação zelar pela probidade e pelo comportamento da esposa. Por conseguinte, embora a ofensa atingisse directamente a mulher, acabava por afectar também, ainda que indirectamente, o marido, uma vez que este não tinha sido capaz de salvaguardar a integridade familiar.

Todavia, os crimes cometidos pelos homens sobre as mulheres não se restringiam à esfera física e moral. Os homens também atacavam as mulheres para se apoderarem de alguns dos seus haveres. Sobretudo mulheres sós, solteiras, viúvas ou casadas com maridos ausentes, eram vítimas da acção de larápios, que tiravam partido da solidão feminina, e assaltavam as suas casas, os seus campos e montes, furtando e roubando o que conseguiam açambarcar.

44 Sobre o mexerico no mundo rural, confira-se L. POLANAH (1993). «Mexerico e maldizer no mundo rural». Revista de Guimarães, n. ${ }^{\circ}$ 103, pp. 111.

45 Num meio fortemente marcado pela emigração masculina, seriam comuns os mexericos referentes ao adultério feminino, devido à maior exposição pública da mulher e aos longos períodos em que esta permanecia afastada do cônjuge. Acerca deste assunto, veja-se J. PINA CABRAL (1989). Filhos de Adão, Filhas de Eva. A visão do mundo camponesa no Alto Minho..., pp. 105-130. 
Quadro 1. Profissões dos arguidos do sexo masculino (1923-1928)

\begin{tabular}{cc}
\hline Profissão & Número de individuos \\
\hline Alfaiate & 1 \\
Alquilador & 1 \\
Amanuense & 1 \\
Cabreiro $^{4}$ & 2 \\
Carpinteiro & 2 \\
Chaufer & 1 \\
Comerciante & 6 \\
Farmacêutico & 1 \\
Ferreiro & 1 \\
Ferroviário & 2 \\
Guarda & 3 \\
Jornaleiro & 5 \\
Lavrador & 27 \\
Madeireiro & 2 \\
Marítimo & 3 \\
Pedreiro & 1 \\
Pescador & 12 \\
Pintor & 3 \\
Polícia & 4 \\
Professor & 1 \\
Proprietário & 10 \\
Regedor & 1 \\
Sapador & 1 \\
Serrador & 2 \\
Soldado & 2 \\
Tendeiro & 1 \\
Trabalhador & 4 \\
\hline ADVC, Registo dos corpos de & $d e l i t o, p r o c e s s o s$ \\
\hline
\end{tabular}

FONTE: ADVC, Registo dos corpos de delito, processos crimes, nos termos da lei, n. ${ }^{\circ}$ 4.91.6.9.

Os agressores, na sua maioria casados, exerciam as mais variadas profissões, embora predominassem os que se dedicavam ao trabalho do campo, como jornaleiros e lavradores, e à faina do mar, como pescadores, como se pode observar no QUADRO 1.

No que se refere aos níveis de literacia, verifica-se que, no caso particular de Caminha, entre os 281 arguidos do sexo masculino, apenas foi mencionada a

${ }^{46}$ Alquilador - aquele que alquila, aluga, sobretudo animais para transporte.

${ }^{47}$ Cabreiro - aquele que guarda cabras. 
formação escolar de 63 , sendo que 45 declaravam que sabiam ler e escrever e unicamente 17 assumiam a sua condição de analfabetos. ${ }^{48}$

As mulheres também eram vítimas de elementos do seu sexo. Aliás, nos concelhos de Caminha e Ponte de Lima, o número de agressões cometido por mulheres sobre mulheres, está muito próximo ou suplanta o número de agressões cometidas por homens sobre mulheres, o que coloca em causa a ideia préconcebida que atribui à mulher apenas o papel de vítima. Entre os delitos praticados, predominam os atentados contra a integridade física e moral, surgindo a larga distância o furto. No caso particular de Caminha, os homens aparecem referenciados como autores de 39 delitos praticados contra as mulheres, ao passo que as mulheres surgem implicadas em 54 acções violentas contra elementos do mesmo sexo. Dentro destas, 27 reportam-se a delitos de ofensa corporal, 21 a crimes de ofensa à moral, três a furto, havendo ainda um caso de ofensa à moral pública, um de apedrejamento e outro de dano. ${ }^{49}$

Em Ponte de Lima, os homens são referidos como autores de 129 acções criminosas exercidas sobre as mulheres, ao passo que estas agem criminalmente contra as suas semelhantes em 87 casos. Relativamente aos crimes cometidos por mulheres sobre mulheres, a primazia vai, mais uma vez, para as ofensas corporais, que representam 58 dos casos, seguindo-se, a larga distância, sete crimes de ofensa corporal e furto, sete de injúrias, seis de ultraje à moral e dano, quatro de fogo posto e um de ameaça. ${ }^{50}$

\section{CONCLUSÕES}

A mulher do Alto Minho, se muitas vezes era vítima da violência masculina, também não deixava de assumir o papel de agressora e de vítima das suas iguais, envolvendo-se em rixas e zaragatas, que tanto podiam acontecer em lugares públicos como em sítios mais recatados. As razões que podiam desencadear cenas de violência eram as mais variadas: injúrias, calúnias, questões relacionadas com a honra pessoal ou familiar, problemas laborais, diferendos pessoais ou com a vizinhança. ${ }^{51}$

${ }^{48} \mathrm{ADVC}$, Registo dos corpos de delito, processos crimes, nos termos da lei, n. ${ }^{\text { }}$ 4.91.6.9.

49 ADVC, Registo dos corpos de delito, processos crimes, nos termos da lei, n. ${ }^{\circ}$ 4.91.6.9.

${ }^{50}$ AMPL, Corpos de delito, n. ${ }^{\circ} 1726$.

51 Acerca dos conflitos que envolveram mulheres de Ponte de Lima, na primeira metade do século XIX, leia-se A. ESTEVES (2009). "Violência e conflitualidade em Ponte de Lima na primeira metade do século XX"..., pp. 306-308. 
Basicamente podemos considerar que há um manancial de situações que colocam a mulher no epicentro do conflito, quer como vítima, quer como protagonista, em resultado da sua maior exposição, decorrente da vivência pública que experimentava no seu quotidiano. A escassa ou nula literacia também não deixava de contribuir para o seu envolvimento em episódios de violência, na medida em que a maior dificuldade em verbalizar as suas emoções acabava por levá-la a agir de forma mais instintiva, caindo mais facilmente em comportamentos agressivos.

Considerados os números respeitantes às ocorrências criminais, somos levados a concluir que, em finais do século XIX e inícios do século XX, Ponte de Lima e Caminha eram concelhos relativamente pacíficos, onde os casos de violência tinham mais a ver com pequenos arrufos, sem a presença de uma violência organizada e premeditada. 